\title{
Bullous pemphigoid and comorbidities: a case-control study in Portuguese patients*
}

\author{
Vera Barreto Teixeira ${ }^{1}$ \\ Ricardo Vieira ${ }^{1}$
}

\author{
Rita Cabral ${ }^{1}$ \\ Américo Figueiredo ${ }^{1}$
}

Maria Manuel Brites ${ }^{1}$

\begin{abstract}
BACKGROUND: Although rare, bullous pemphigoid (BP) is the most common autoimmune blistering disease. Recent studies have shown that patients with bullous pemphigoid are more likely to have neurological and psychiatric diseases, particularly prior to the diagnosis of bullous pemphigoid. OBJECTIVE: The aims were: (i) to evaluate the demographic and clinical features of bullous pemphigoid from a database of patients at a Portuguese university hospital and (ii) to compare the prevalence of comorbid conditions before the diagnosis of bullous pemphigoid with a control group. METHODS Seventy-seven patients with bullous pemphigoid were enrolled in the study. They were compared with 176 age- and gender-matched controls, which also had the same inpatient to outpatient ratio, but no history of bullous or cutaneous malignant disease. Univariate and multivariate analyses were used to calculate odds ratios for specific comorbid diseases. RESULTS: At least one neurologic diagnosis was present in $55.8 \%$ of BP patients compared with $20.5 \%$ controls $(\mathrm{p}<0.001)$. Comparing cases to controls, stroke was seen in 35.1 vs. 6.8\%, OR 8.10 (3.80-17.25); dementia in 37.7 vs. 11.9\%, OR 5.25 (2.71-10.16); and Parkinson's disease in 5.2 vs. 1.1\%, OR 4.91 (0.88-27.44). Using multivariate analysis, all diseases except Parkinson's retained their association with BP. Patients under systemic treatment were eight times more likely to have complications than those treated with topical steroids $(\mathrm{p}<0.017)$. ConCLUSIONS: The results of this study substantiate the association between BP and neurological diseases. In addition, they highlight the potential complications associated with the treatment of BP.
\end{abstract}

Keywords: Comorbidity; Nervous system diseases; Neurologic manifestations; Pemphigoid, bullous; Portugal

\section{INTRODUCTION}

Bullous pemphigoid (BP) is the most common autoimmune blistering disease and predominantly affects the elderly. ${ }^{1-3}$ However, on rare occasions, it can be present in young adults and children. ${ }^{4}$ Both genders are equally affected. The annual incidence of BP has been estimated to range from 2 to 14 new cases per million people. ${ }^{1,3,5-6}$ Its incidence is expected to rise as a consequence of population ageing. A recent study in France found a 3-fold increase in the annual incidence of BP over the last 15 years, with 21.7 new cases per million inhabitants. ${ }^{7}$

$\mathrm{BP}$ is characterized by the presence of circulating IgG autoantibodies directed against two proteins of the basement membrane zone, bullous pemphigoid antigens 1 and 2 (BPAG1 and BPAG2), which are detectable by both direct and indirect immunofluorescence. However, pathogenesis is still not completely understood. Previous studies have suggested a relationship between BP and comorbid conditions like neurological and psychiatric diseases, diabetes mellitus, and malignancy. ${ }^{8-12}$ Recently, a prospective casecontrol study, which evaluates risk factors for BP, identified neurological disorders, namely dementia and Parkinson's disease, psychiatric disorders (unipolar and bipolar disorders), bedridden condition, and chronic use of several drugs, as risk factors for BP. ${ }^{13}$

Systemic corticotherapy (prednisone $0.5-1 \mathrm{mg}$ per kilogram of body weight per day) is considered the standard treatment, but serious adverse effects can occur, including death, particularly in elderly patients. ${ }^{14-18}$ In spite of the progress in BP treatment, the mortality rate of these patients can be up to sixfold higher than in the general population. ${ }^{7}$

\footnotetext{
Received on 05.02.2013.

Approved by the Advisory Board and accepted for publication on 06.04.2013.

* Work performed at the Hospitais da Universidade de Coimbra (HUC) - Coimbra, Portugal.

Financial Support: None

Conflict of Interest: None

Coimbra University Hospital, Portugal.
} 
In 2002, Joly et al conducted a large controlled clinical trial, which demonstrated that high potency topical steroids improve survival in patients with extensive $\mathrm{BP}$, as compared with oral corticosteroid therapy. ${ }^{19}$

\section{Objective}

The primary endpoint of the present study was to determine the prevalence and association of comorbid conditions with BP in patients who had medical attendance at our hospital.

\section{MATERIALS AND METHODS}

This case-control study was approved by the research ethics board of Coimbra University Hospital. Between January 1998 and December 2010, we identified, in our department, all individuals who had undergone a histological procedure $(n=97)$ on the basis of clinical suspicion of BP. From this initial cohort, we performed a manual chart review, abstracting medical records individually to ensure that these patients fulfilled the following three criteria: (1) typical clinical features, such as tense blisters on both the normal and erythematous bases, (2) characteristic histopathologic findings, such as subepidermal blisters and (3) immunological findings of positive direct immunofluorescence (DIF) tests (linear IgG and/or C3 deposits along the epidermal basement-membrane zone). Of the ninety-seven patients identified as potentially eligible cases, we excluded 20 patients who did not meet these inclusion criteria, thus the sample for this study comprised 77 patients. The following data were recorded: age at diagnosis, gender, degree of autonomy, clinical features, laboratorial parameters, therapy adopted, concomitant medications and comorbidities (neurological and psychiatric disorders, hypertension, diabetes mellitus, thyroid dysfunction, psoriasis, leg ulcers or other chronic wounds, history of fracture or joint-replacement surgery). One hundred and seventysix controls ( $\sim 2$ for each BP patient) were randomly selected from the list of our clinical folders, excluding patients with a diagnosis of bullous or cutaneous malignant disease, and matched according to age, sex and inpatient to outpatient ratio.

\section{Statistical analysis}

Statistical analysis was performed using the Software Package for Statistical Science (SPSS for Windows, version 18.0, Chicago, IL). Continuous data are presented as the mean value and standard deviation (SD), and categorical variables are presented as percentages. Patients and control subjects were compared using the Student's t-test for continuous variables, while the Pearson Chi-square test was applied for categorical variables. Univariate logistic regression was used to calculate the crude odds ratios (OR) and
95\% confidence intervals (CI) for comorbid conditions in relation to BP. A logistic regression model was used to measure the association between $\mathrm{BP}$ and neurological disorders in a multivariate analysis.

\section{RESULTS}

The median (range) age at presentation for BP was 79.6 (SD 8.3) years. The age distribution ranged from 49 to 96 years. Thirty nine $(50.6 \%)$ of the patients were female and $38(49.4 \%)$ were male. The age, age group and gender distributions of the cohort are presented in Table 1. Control patients were well matched in terms of age $(p=0.64)$, gender $(p=0.51)$, and had the same inpatient to outpatient ratio $(p=0.19)$. Controls had various cutaneous diseases (erysipela/cellulitis, leg ulcer, drug eruption, eczema, psoriasis and vasculitis), as illustrated in Graph 1.

TABLE 1: Demographic features of cases and controls

\begin{tabular}{clll}
\hline Characteristic & Cases & Controls & P-value $^{*}$ \\
& $\mathbf{n}=\mathbf{7 7}$ & $\mathbf{n}=\mathbf{1 7 6}$ & \\
Age (mean), years & 79.6 & 79.1 & $0.64 \dagger$ \\
Age group, n (\%) & & & $0.22 \ddagger$ \\
$<60$ & $1(1.3)$ & $2(1.1)$ & \\
$60-69$ & $8(10.4)$ & $9(5.1)$ & \\
$70-79$ & $32(41.6)$ & $92(52.3)$ & \\
$\geq 80$ & $36(46.7)$ & $73(41.5)$ & \\
Gender, n (\%) & & & $0.51 ¥$ \\
$\quad 0$ & $38(49.4)$ & $79(44.9)$ & \\
$\quad$ \% & $39(50.6)$ & $97(55.1)$ & \\
Input patients, n (\%) & $62(80.5)$ & $128(72.7)$ & $0.19 ¥$ \\
\hline
\end{tabular}

*P- value of the T student test $(\dagger)$, Fisher's exact test ( $\ddagger$ ) or Chi-Square test $(¥)$, as appropriate.

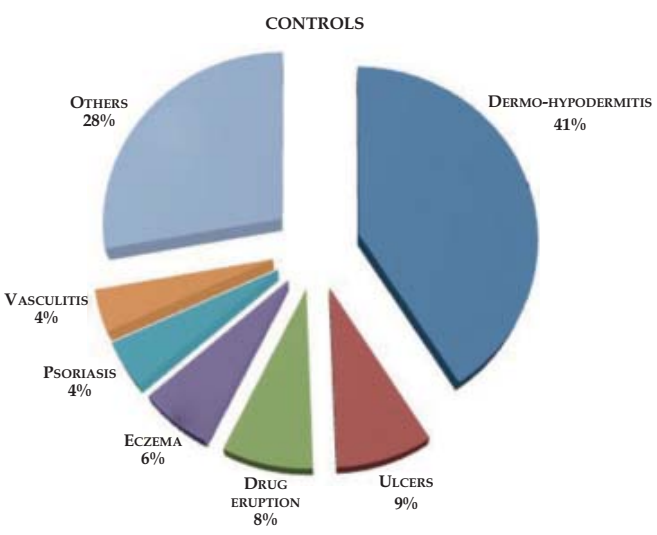

GraPH 1: Diseases of the controls 
Chronic treatment with at least one drug before onset of BP was observed in $87 \%$ of cases, namely diuretics (48.1\% of BP patients), angiotensin-converting enzyme inhibitors/angiotensin II receptors antagonists $(40.3 \%)$ and benzodiazepines (35.1\%) (Table 2).

Upon diagnosis, all patients had cutaneous blisters and 34 patients $(44.2 \%)$ also had urticarial plaques. In addition, the oral mucosa of 11 patients $(14.3 \%)$ were affected, while $92.2 \%$ complained of pruritus. About half of the cases involved peripheral blood eosinophilia (50.6\%) (Table 3).

About one fifth of patients $(20.8 \%)$ was successfully treated with high-potency topical steroids in monotherapy. The rest also received systemic treatment, mainly oral corticosteroids (57.1\%). Dapsone was the second most prescribed systemic drug, alone or concurrently with oral corticosteroids (Table 4). Some patients treated with dapsone $(11.4 \%)$ experienced side effects: hemolysis and anemia (data not shown).

TABLE 2: Chronic medication (at least one drug in the last three months) in BP patients

\begin{tabular}{ll}
\hline Chronic medication & BP patients $(\mathbf{n}=\mathbf{7 7})$ \\
\hline Chronic medication & number (\%) \\
Diuretics & $37(47)$ \\
$\quad$ Furosemide & $21(27.3)$ \\
$\quad$ Thiazides & $17(22)$ \\
$\quad$ Spirolactone & $2(2.6)$ \\
Angiotensin-converting enzyme inhibitors/angiotensin II \\
receptor antagonists & $31(40.3)$ \\
Benzodiazepines & $27(35.1)$ \\
Neuroleptics & $24(31.2)$ \\
Antiarrhytmics & $14(18.2)$ \\
NSAIDs & $5(6.5)$ \\
Calcium channel blockers & $4(5.2)$ \\
Statins & $4(5.2)$ \\
Fenofibrates & $1(1.3)$ \\
\hline
\end{tabular}

Abbreviations: NSAIDs, nonsteroidal anti-inflammatory drugs.

TABLE 3: Clinical characteristic of BP patients

\begin{tabular}{lll}
\hline Characteristic & \multicolumn{2}{l}{ Number (\%) } \\
\hline & \multicolumn{2}{l}{$\mathbf{n = 7 7}$} \\
Pruritus & 71 & $(92.2)$ \\
Type of lesions & & \\
tense blisters & 47 & $(61)$ \\
urticarial plaque & 34 & $(44.2)$ \\
eczematous lesions & 8 & $(1)$ \\
Mucosal lesions & 11 & $(14.3)$ \\
Eosinophilia (eosinophil $>600$ cell/uL) & 39 & $(50.6)$ \\
\hline
\end{tabular}

Complications occurred in 25 patients (32.5\%), mainly infections (urinary tract infection, respiratory infection and erysipela/cellulitis) and decompensation of diabetes, which affected 20.8 and $14.3 \%$ of BP patients, respectively. In 3 patients, the infection progressed to sepsis, with fatal outcomes for 2 of them. BP patients who underwent systemic treatment were eight times more likely to have complications than patients who only received topical corticosteroids $(\mathrm{p}<0.017)$.

Clinical remission was achieved in a mean of 42.7 days (SD 29). Twenty-two patients were lost to followup. Of the $55 \mathrm{BP}$ patients who were still in follow-up, 27 $(49.1 \%)$ experienced at least one relapse. The mean interval until relapse was 4.4 months. BP patients were kept in follow-up for a mean of 8.5 months (SD 11).

Table 5 shows the univariate comparison of cases and controls. $44.2 \%$ of patients (34 BP) were in a bedridden condition, compared with $13.6 \%$ (24) of the controls (OR 5.2, 95\% CI 2.8-9.8). Also, BP patients had been hospitalized for a longer period of time compared to controls (mean 20.5 vs 13.2 days, $\mathrm{p}<0.001$ ).

Eight $(11 \%)$ BP patients had a prior diagnosis of malignancy, namely prostate cancer (2 patients) and lymphoproliferative disorders (2 patients) (data not shown). No statistical difference was found between cases and controls.

At least one neurological disease was present in $55.8 \%$ (43) of BP cases before the diagnosis of BP compared with $20.5 \%$ (36) of controls (OR 5.36, 95\% CI 2.97-9.66). BP patients had significantly increased odds for cerebral stroke (OR 8.10, 95\% CI 3.80-17.25), dementia (OR 5.25, 95\% CI 2.71-10.16) and Parkinson's disease (OR 4.91, 95\% CI 0.88-27.44). However, the association with Parkinson's disease became non-statistically significant after correction for multiple testing (Table 6).

No association was found between BP and Alzheimer's disease, depression and diabetes mellitus. Controls were more likely than BP patients to have hypertension ( 2.17 odds).

\section{DISCUSSION}

We found an association between BP and neurological disorders (dementia and cerebral stroke), which remained to be independently associated with BP by multivariate analysis. Parkinson's disease missed its association, probably due to the small num-

TABLE 4: Treatment modalities

\begin{tabular}{lc}
\hline Treatment modalities & $\mathbf{n}, \mathbf{( \% )}$ \\
\hline Topical corticosteroids & $77(100)$ \\
Oral corticosteroids & $44(57.1)$ \\
Dapsone & $35(45.5)$ \\
Azathioprine & $6(7.7)$ \\
Methotrexate & $3(3.9)$ \\
\hline
\end{tabular}


TABLE 5: Univariate comparison of cases and controls

\begin{tabular}{lclll}
\hline & $\begin{array}{l}\text { Cases } \\
(\mathrm{n}=77)\end{array}$ & $\begin{array}{l}\text { Controls } \\
(\mathrm{n}=176)\end{array}$ & OR (95\% CI $)^{1}$ & P-value $^{2}$ \\
\cline { 2 - 5 } Neurological disease & $43(55.8)$ & $36(20.5)$ & $5.36(2.97-9.66)$ & $<0.001$ \\
Dementia & $19(37.7)$ & $21(11.9)$ & $5.25(2.71-10.16)$ & $<0.001$ \\
Cerebral stroke & $27(35.1)$ & $12(6.8)$ & $8.10(3.80-17.25)$ & $<0.001$ \\
Parkinson's disease & $2(1.1)$ & $4(5.2)$ & $4.91(0.88-27.44)$ & 0.046 \\
Alzheimer's disease & $2(2.6)$ & $2(1.1)$ & - & - \\
Depression & $8(10.4)$ & $10(5.7)$ & - & - \\
Hypertension & $45(58.4)$ & $135(76.7)$ & $0.46(0.26-0.83)$ & 0.008 \\
Diabetes mellitus & $20(26.0)$ & $46(26.1)$ & - & - \\
Ulcers & $6(7.8)$ & $38(21.6)$ & $0.31(0.13-0.77))$ & 0.009 \\
Past fracture or joint-replacement surgery & $12(15.6)$ & $27(15.3)$ & - & - \\
Malignancy & $8(10.4)$ & $31(17.6)$ & - & - \\
Chronic medication & $67(87.0)$ & $165(93.2)$ & - & - \\
Bedridden condition & $34(44.2)$ & $24(13.6)$ & $5.22(2.79-9.76)$ & $<0.001$ \\
Length of hospitalization (in days, range) & 20.5 & 13.3 & - & $<0.001$ \\
Complications & $25(32.2)$ & $22(12.5)$ & $2.46(1.26-4.80)$ & 0.007 \\
\hline
\end{tabular}

1 - Odds ratios with $95 \% \mathrm{CI}$.

2 - P-value of the Pearson Chi-square test.

TABLE 6: Multivariate logistic regression for the association between neurological disorders and BP patients

\begin{tabular}{lll} 
& OR $(95 \% \mathrm{CI})$ & P-value \\
\cline { 2 - 3 } Dementia & $4.13(1.42-14.56)$ & $<0.001$ \\
Cerebral stroke & $5.22(1.65-15.51)$ & $<0.001$ \\
Parkinson's Disease & - & 0.148 \\
Age & & 0.651 \\
Gender & & 0.619 \\
\hline
\end{tabular}

Odds ratios were adjusted for matching variables (age, gender) and neurological disorders.

ber of patients in our cohort. Our results confirmed earlier findings of a higher prevalence of neurological diseases among BP patients when compared with the general population. In France, 36\% of BP patients were diagnosed with at least one neurological disorder, namely dementia, in $20 \%$ of BP patients. ${ }^{8,13}$

These associations have been widely investigated in recent years. The hypothesis of immunological cross-reactivity between the neuronal isoform of BPAG1 and its epithelial isoform, seems to explain those associations. Neurological diseases could expose the neuronal isoform and trigger a subsequent immunological reaction that causes the cutaneous lesions. Further studies are needed to better understand the underlying molecular pathways. ${ }^{20}$

The relationship between BP and malignancy has been under debate for many years and is still controver- sial. Some reports have suggested an increased frequency of certain carcinomas (e.g. stomach, colon, prostate, breast and lung) as well as lymphoproliferative disorders. . $221-^{-21}$ ${ }^{23}$ As BP affects predominantly the elderly, it was expected that there would be a higher frequency of malignancies than in the general population. In 1990, Venning et al reported that the rate of malignant disease was higher in BP patients $(17.9 \%)$ compared with matched controls $(5.3 \%) .{ }^{21}$ Ogawa et al studied a large Japanese population of BP patients (1113 patients) and found malignant disease in $5.8 \%$ of patients compared with $0.61 \%$ among controls. ${ }^{12}$ However no statistical analysis was conducted to clarify these findings. In addition, other authors found no link between $\mathrm{BP}$ and malignancy. ${ }^{24,25}$ In our control group, all patients whose reason for consultation or hospital admission was cutaneous malignancy, were excluded., Even removing this bias, we did not find any association between malignancy and BP. We agree with some authors who recommend cancer screening when there are systemic manifestations and atypical presentations, such as onset in a middle-aged person.Also, BP patients should have regular cancer screening tests as recommended for the general population.

Chuang et al reported an association between $\mathrm{BP}$ and diabetes, showing $20 \%$ diabetic BP patients versus $2.5 \%$ diabetic controls $(p=0.004) .{ }^{11}$ This was supported by other studies. ${ }^{26-27}$ It has been proposed that an autoimmune response occurs after exposure of the BP antigens, by glycation of proteins of the dermoepidermal junction. Like other authors, we did not 
find an association between BP and diabetes. ${ }^{24}$ Further studies are needed to clarify this issue.

Systemic corticosteroid treatment is the most common treatment for BP patients. ${ }^{14}$ However, BP treatment is not devoid of side effects and is often responsible for the exacerbation of associated diseases in the elderly population. Thus, a careful judgment should be made before starting any treatment. In our study, BP patients under systemic treatment experienced more complications compared with those treated using topical corticosteroids. In this context, two fatal outcomes occurred. In a previous study, sepsis represented the main cause of death in BP patients. ${ }^{16}$ It is interesting to note that all patients treated with topical corticosteroids, in addition to clinical remission, experienced no major complications.

Our study has some limitations, such as the ret-

\section{REFERENCES}

1. Bernard P, Vaillant L, Labeille B, Bedane C, Arbeille B, Denoeux JP, et al. Incidence and distribution of subepidermal autoimmune bullous skin diseases in three French regions. Bullous Diseases French Study Group. Arch Dermatol. 1995;131:48-52.

2. Jung M, Kippes W, Messer G, Zillikens D, Rzany B. Increased risk of bullous pemphigoid in male and very old patients: a population-based study on incidence. J Am Acad Dermatol. 1999;41:266-8.

3. Langan SM, Smeeth L, Hubbard R, Fleming KM, Smith CJ, West J. Bullous pemphigoid and pemphigus vulgaris: incidence and mortality in the UK: population based cohort study. BMJ. 2008;337:a180.

4. Quattrino AL, Silveira JCGS, Kawakubo SW, Xavier V, Rochael MC. Bullous pemphigoid in childhood. An Bras Dermatol. 2007;82:87-9.

5. Bertram F, Bröcker EB, Zillikens D, Schmidt E. Prospective analysis of the incidence of autoimmune bullous disorders in Lower Franconia, Germany. J Dtsch Dermatol Ges. 2009;7:434-40.

6. Gudi VS, White MI, Cruickshank N, Herriot R, Edwards SL, Nimmo F, et al. Annual incidence and mortality of bullous pemphigoid in the Grampian Region of North-east Scotland. Br J Dermatol. 2005;153:424-7.

7. Joly P, Baricault S, Sparsa A, Bernard P, Bédane C, Duvert-Lehembre S, et al. Incidence and Mortality of Bullous Pemphigoid in France. J Invest Dermatol. 2012;132:1998-2004.

8. Cordel N, Chosidow 0, Hellot MF, Delaporte E, Lok C, Vaillant L, et al. Neurological disorders in patients with bullous pemphigoid. Dermatology. 2007;215:187-91.

9. Langan SM, Groves RW, West J. The relationship between neurological disease and bullous pemphigoid: a population-based case-control study. J Invest Dermatol. 2011:131:631-6.

10. Chen YJ, Wu CY, Lin MW, Chen TJ, Liao KK, Chen YC, et al. Comorbidity profiles among patients with bullous pemphigoid: a nationwide population-based study. $\mathrm{Br} \mathrm{J}$ Dermatol. 2011;165:593-9.

11. Chuang TY, Korkij W, Soltani K, Clayman J, Cook J. Increased frequency of diabetes mellitus in patients with bullous pemphigoid: a case-control study. J Am Acad Dermatol. 1984;11:1099-102.

12. Ogawa H, Sakuma M, Morioka S, Kitamura K, Sasai Y, Imamura S, et al. The incidence of internal malignancies in pemphigus and bullous pemphigoid in Japan. $J$ Dermatol Sci. 1995;9:136-41.

13. Bastuji-Garin S, Joly P, Lemordant P, Sparsa A, Bedane C, Delaporte E, et al. Risk factors for bullous pemphigoid in the elderly: a prospective case-control study. J Invest Dermatol. 2011;131:637-43.

14. Kirtschig G, Middleton P, Bennett C, Murrell DF, Wojnarowska F, Khumalo NP. Interventions for bullous pemphigoid. Cochrane Database Syst Rev. 2010;CD002292.

15. Korman NJ. Bullous pemphigoid: the latest in diagnosis, prognosis, and therapy. Arch Dermatol. 1998;134:1137-41. rospective chart analysis and the relatively small number of patients. Further, we could not conclude anything about BP incidence because a considerable number of BP patients were not submitted to histological and immunofluorescence studies, and therefore were not included in this study.

\section{CONCLUSIONS}

We identified an association between neurological diseases and BP in Portuguese patients, supporting associations found in previous studies. This association is of interest due to the possible role in BP etiology. Further research is required to elucidate these findings.

\section{ACKNOWLEDGMENTS}

The authors wish to thank Dr. Margarida Marques for the statistical analysis.

16. Roujeau JC, Lok C, Bastuji-Garin S, Mhalla S, Enginger V, Bernard P. High risk of death in elderly patients with extensive bullous pemphigoid. Arch Dermatol. 1998; 134:465-9

17. Bernard P, Enginger V, Venot J, Bedane C, Bonnetblanc JM. Pronostic vital de la pemphigoïde: analyse d'une cohorte de 78 malades. Ann Dermatol Venereol. 1995; 122:751-7

18. Rzany B, Partscht K, Jung M, Kippes W, Mecking D, Baima B, Risk factors for lethal outcome in patients with bullous pemphigoid: low serum albumin level, high dosage of glucocorticosteroids, and old age. Arch Dermatol. 2002;138:903-8.

19. Joly P, Roujeau JC, Benichou J, Picard C, Dreno B, Delaporte E, et al. A comparison of oral and topical corticosteroids in patients with bullous pemphigoid. N Engl J Med. 2002;346:321-7.

20. Chen J, Li L, Chen J, Zeng Y, Xu H, Song Y, et al. Sera of elderly bullous pemphigoid patients with associated neurological diseases recognize bullous pemphigoid antigens in the human brain. Gerontology. 2011;57:211-6.

21. Venning VA, Wojnarowska $F$. The association of bullous pemphigoid and malignant disease: a case control study. Br J Dermatol. 1990;123:439-45.

22. Umekoji A, Tsuruta D, Inoue T, Nishimori T, Ishii M. Bullous pemphigoid as a dermadrome associated with spindle cell carcinoma of the gallbladder. J Dermatol. 2010;37:251-4.

23. Yanagi T, Kato N, Yamane N, Osawa R. Bullous pemphigoid associated with dermatomyositis and colon carcinoma. Clin Exp Dermatol. 2007;32:291-4.

24. Jedlickova H, Hlubinka M, Pavlik T, Semradova V, Budinska E, Vlasin Z. Bullous pemphigoid and internal diseases - A case-control study. Eur J Dermatol. 2010;20:96-101.

25. Wanker NCF, Bedran JL, Nascimento MCF, Gurgel PJC, Paz PAL, Macieira JMP. Penfigóide bolhoso e câncer. An Bras Dermatol. 1992;67:11-3.

26. Rosina P, Chieregato C, D'Onghia FS. Bullous pemphigoid and diabetes mellitus. Acta Derm Venereol. 1996;76:497-8

27. Kulthanan K, Chularojanamontri L, Tuchinda P, Sirikudta W, Pinkaew S. Prevalence and clinical features of Thai patients with bullous pemphigoid. Asian Pac J Allergy Immunol. 2011;29:66-72.

MAILING ADDRESS:
Vera Barreto Teixeira
Serviço de Dermatologia
Praceta Mota Pinto
3000-075 - Coimbra
Portugal
E-mail: vera.teixeira.derm@gmail.com

How to cite this article: Teixeira VB, Cabral R, Brites MM, Vieira R, Figueiredo A. Bullous pemphigoid and comorbidities: a case-control study in portuguese patients. An Bras Dermatol. 2014;89(2):274-8. 